\title{
Assessment of Acceptance and User Experience of Human-Computer Interaction with a Computer Interface
}

\author{
https://doi.org/10.3991/ijim.v14i11.13943 \\ Nidal Al Said ${ }^{(\varpi)}$ \\ Ajman University, Ajman, United Arab Emirates \\ n.alsaideajman.ac.ae \\ Khaleel M. Al-Said \\ Middle East University, Amman, Jordan
}

\begin{abstract}
The study aims to determine the impact of human-computer interface design on the development of mobile phones. The researcher used the descriptive analytical approach. The result shows the importance of smartphone such as communication with others, define the most important standards of application design such as efficiency and speed and determine the disadvantages of smartphones such as sleep problems and fatigue. In addition to, the study defines the $\mathrm{HCI}$ as science examines the design and use of computer technology, focusing on interfaces between people (users) and computers and determine the popular challenges which face HCI such as HCI designers face important challenges in how to ensure their design provides good HCI. The study recommended the need for further studies that support mobile phone and to deal with new platforms for iOS and Android, making usability tests for programs, applications and websites and qualify and train users with cognitive deficits in an appropriate manner to enable them to make better use of programs and applications.
\end{abstract}

Keywords-Design, Human-Computer Interface, Mobiles Devices.

\section{Introduction}

The interaction between humans and computers is a wide area of research and practice, a study of interaction between users and computers [1, 2]. In the last century, he began as a field of computer science, considered a branch of science and worried with the manufacture and design of systems for human usage all questions related to everything that interferes with those things. The user comes in the introduction to this integrated circuit so that the elements reflect what the user is doing.

This has become an important field of study, as it relates to many areas of human interaction with the computer such as interaction for educational, medical, commercial, economic, scientific and research purposes. In addition to the great interaction between people and devices in the field of entertainment and games through applications widely deployed, especially on mobile devices [3]. 
Mobile technology has grown tremendously in the interaction between humans and computers because it has become a major part of our daily life. The availability of (highresolution screens) makes hardware extremely useful. However, an individual's ability to utilize these devices acting a key part when it respects to software design that achieve the human-computer communication with mobile devices. To achieve ease of usage in UI of the system, and it is indispensable to confirm the quality of usage through the improvement process [4].

The problem of study is determined by the use of mobile devices in different castigations, like medicine, teaching, and sociology. Therefore, it is essential to focus primarily about how the user interaction with the mobile device. Due to the emergence of new versions of products due to the increasing need for users and ease of use. Where users are looking for new ways to develop mobile performance based on consumer desires and the ability to interact with a mobile device. The importance of the study is shown by contributing to the development of the skills and expertise of designers who are working to develop their skills through the creation of new mobile devices or development on previous devices. Smartphone applications also perform many transactions such as paying electricity bills, using maps to get a location where you want to go.

\section{Literature Review}

The subject of human-computer interaction is one of the broad areas of study and exercise. It developed as a beginning in the primary 1980s, where it began as a field of specialization in information technology, including mental science and engineering of human feature, and quickly extended to attract experts from other disciplines. And concepts. As a result of the integration of many different concepts and trends, human and computer interaction gave a significant model of the probability of merge various methods into a dynamic and creative intelligent method in human-centered information. Where it facilitates the integration of different models to form a product model.

The evolution of human interaction with the computer after the emergence of personal computers, and became a large number of computer users, as a result of containing personal programs (interactive games, editing texts) and some platforms (operating systems, programming languages). In the late 1970s, the Knowledge Science Project was launched with the aim of clarifying systematic and scientific applications. At that time, PC demonstrated its need for hi ci, where he introduced human cognitive science and skills to meet these needs by combining science and engineering [5].

Human Processor method was a primary mental engineering method designed to support designer's implementation the rules from mental psychology.

$\mathrm{HCI}$ is realize as the survey of interpersonal relationship with the laptop systems and the applications them usage every day. This can range from using a PDA to downloading information about the HCI module that you may study as part of your undergraduate education, to update the credit balance on your mobile phone [6]. And It is defined as "a specialty interested with designing, testing and application of interacting methods 
used by man and related phenomena. It is the study of the interactive the user with the software and hardware computer systems [7].

The objectives Of HCI are as follows [7]:

- Security: Keeping the user against dangerous cases and unwanted states.

- Users: Workers must react with computer-based models remotely medicinal tools in intensive care unit (ICU).

- Data: Deny the user from creating dangerous mistakes via decrease danger of activating incorrect keys/buttons. Equipping user with wherewithal of improving mistakes. Guarantee privacy (keep individual information like behaviors and address) \& safety (keep critical information like passwords, the numbers of VISA card).

- Efficiency: Attention to the ability of the user to achieve a wanted aim or to carry out work.

By reviewing HCI project rules, six project rules were recognized, such as: recoverability; knowledge; reliability; substitutivity; taskmigratability; and perceptual ergonomics [8].

1. Recoverability: Where the user can recover from a common error. It includes two kinds of mistake retrieval (forward and backward). In forward retrieval: the user's ability to deny the mistake; in the back-to-back: the user's ability to reverse the error.

2. Knowledge: Contributes to determining the user's knowledge of the model and matches the suitable or specific method to use the model.

3. Reliability: How the user handles or how to complete tasks in like states. And how the user addresses the input and output facilities of the system.

4. Substitutivity: Provides the user with an option or alternative to performing a task by selecting any of the available options.

5. Taskmigratability: Allows the system to perform the task that a user can perform. Where the user transmissions several tasks to the system.

6. Perceptual ergonomics: The system can identify human opinions. The interface must have a control feature for how the user knows objects.

\subsection{Implications of HCI for science, practice, and epistemology}

The evolving method of integrating study and exercise is the generality significant achievement of HCI. The method was shown to be a mutual link between mental science and mental engineering. Ethnographic methods were subsequently directed to human activity, including design, technology development and customization activities. The model now includes extensive design and research practices, such as user experience and environmental sustainability. While HCI was constantly spoken as a design knowledge or as a guiding guide for creators, this was initially explained with HCI study and design as discrete contribution areas of expert experience [9].

The designers of the HCI public were welcomed in phase to support redesign it as a design system. It was aspect of this conversion, doing creating design specialties and problems that did not exist before. Like, the design of user experience and interface was not bringing in into HCI, but was between the first transfers of HCI to the world of 
design. Correspondingly, the examination of productive strains among imagination and logical reasoning in design requires a design area such as HCI where designs need to have interior logic, can be methodically calculated and preserved, and concurrently evokes novel knowledges and ideas. During the improvement of HCI, methodical and cognitive reviews have been intentionally adopted through a domain, via any measure, which manage intelligently and virtually. The effect has been a progressively mobile and difficult area that has continual to be more successful. This example contrasts with Cohen's view on how intelligent tasks evolve by models that are finally dropped. Thus, the continued achievement of the HCI public in touching its forward-looking task has deep effects, not only on human-centered informatics but also on knowledge theory as a whole [10].

Smartphones and their applications are among the most widely used technology tools in the society and play a vital and important role in our daily lives. The most important features used to classify smart phones and their applications are the operating system in which they operate and their applications. Smart phones and their applications rely on technology companies and their applications, Apple and Google.

The Smartphone is a mobile phone that provides more progressive computing and communication capabilities than regular mobile phones. Smart mobile phones and regular mobile phones may be a mobile phone-based mobile phone, a telecommunications service, but mobile phones Allows users to download programs, smart phones enable the user to download and use more complex applications than ordinary mobile phones [11].

Apps for mobile phones can be defined as: software designed to run smartphones or taplets. They are widely distributed in the community and play an important role in our daily lives, enabling the user to carry out his daily tasks as if on his personal computer such as browsing and using personal e-mail. These applications are available on smart phone application stores such as Google Play Store, Apple Store and others, and the development of smart phone applications and their design depends on the type of device itself [12].

Competitors compete for operating systems for smart phones, and vary from one company to another, but agree with each other to compete to meet the user's needs and needs and work on the development and ease of use. "Smartphone is a group of guidelines and directives that work with each other to manage the phone and its different components like the screen, the CPU, camera, or in other words is the relation among devices components and software applications that allow the user to accept benefit of the phone, As when we select an operating system what will determine the applications, games, screen interface and each thing internal the phone [13].

\subsection{Some of the operating systems are smart phone applications}

The operating system consists of the program responsible for controlling and supporting the mobile device (Table 1). 
Table 1. Comparison between the three major mobile platforms.

\begin{tabular}{|l|l|l|l|l|}
\hline \multicolumn{1}{|c|}{ Vendor } & \multicolumn{1}{|c|}{ Platform } & $\begin{array}{c}\text { Programming } \\
\text { language }\end{array}$ & \multicolumn{1}{|c|}{ Improvement Environment } & $\begin{array}{c}\text { Application } \\
\text { Store }\end{array}$ \\
\hline Google & Android & Java & Eclipse /Android/Studio/ Intellij/ IDEA & Google Play \\
\hline Apple & Ios & Objective -C & Xcode & App Store \\
\hline Microsoft & Windows phone & C\#/C++ & Visual Studio & $\begin{array}{l}\text { Windows } \\
\text { Phone Store }\end{array}$ \\
\hline
\end{tabular}

IOS phones are owned by Apple and are examples of a smart phone for iPhone.

- IOS: Is an Apple smartphone operating system for its owner, Jobs Steve, and has pioneered the manufacture and design of computer programs in addition to other electronics such as Ipad, IPhone, Apple TV, all of which are touch-enabled and subject to constant updates, Apple Store [14].

Android phones owned by Google Inc. google Examples of its smartphones Samsung Samsung phones.

- Android: Is an operating system for Google, which supports many smart phones produced by different companies such as: Samsung and HTC, which is an open source system, has been produced by Google in 0223, meaning Android in human form, and subject to constant updates so called Each update has a different name such as Bean Gelly, Marshmello, Lollipop, and the app store is called Play Store [14].

- Windows Phone: Is a special portable operating system developed by Microsoft. WP was released in 2010 with new key features, a completely new graphical interface that uses a design language known as Metro, and allows full integration with Microsoft services, such as Windows Live, or third-party services such as Facebook [15].

The development of mobile phone applications faces a number of challenges as follows [16]:

- The incongruity of hardware utilities: One of the key challenges in mobile application development is that there are many standards for mobile platforms, and there are many smartphones that have excellent hardware qualifications like the size of screen and storage capability.

- Heterogeneity of platforms: Every program utilizes its own programming language and offers various improvement tools for application development. Such as, while Android uses Java, its usages IOS Objective-C, Incompatibility between the platforms, due to the existence of different programming languages, which leads them to rewrite the application of each basic system to increase the effort and time required to market the application. If an $\mathrm{iOS}$ application is required, it requirements high-tech skills in Objective-C, and if an Android application is required, it must have Java experience.

- Recurrent Version Releases: Android utilize an open source operating system, on the other hand, there segmentation for several version of Android and some 
industrialists change the source code of the operating system to their hardware specifications. This is causing problems with less transportability from one version to another and more complex to application improvement. Repeated versions of the mobile operating system are another problem. Programmers should study various programming languages and APIs for these split systems and be constantly updated with SDK updates.

Mobile devices vary widely from desktop and laptop computers in terms of [12]:

1. Mobile devices run on battery and have less computational power than personal computers.

2. It has the ability to detect the location (GPS) and use the camera.

3. Users tend to use desktop applications for long sessions, while mobile app users tend to use them frequently, but for short sessions.

4. Quick start and response are important features for good mobile applications.

5. All of these features can be available in a high-productivity user mobile experience.

Nelson suggests that UI developers must beginning UI models to improve their systems. The overall objective of the patterns is to design a list of solutions to assistance UI designers solve difficult user interface issues.

Software architecture has adopted patterns as a means of facilitating software reuse, where reuse of the software has been extensively studied in previous literature. From checking the nature of the program, in that it demonstrates that the code is extremely monotonous and, in real, more than usual. Evidence has shown that code use again is a popular exercise in software engineering. Large and surprising icons are prone to repetition. Consequently, software use again is a common popular in software engineering [12]:

The neglect of developers in the significance of user interface design is one of the main causes why users renounce the development of mobile applications and personal computer guidance. UI designers have also famous sure design challenge's over and over again by achieving the similar objective as software engineering studies to use again codes. We also look at how to reuse the UI in Android apps in 8 various classes (e.g., Shopping, Social, Finance, Weather, News, Travel, Transport, and Health [17].

\section{Methodology}

The researcher used the descriptive and statistical approach in this study by studying the previous studies that dealt with the concept of interaction between man and computer and his role in the development of mobile phone and used two questionnaires for both users and developers. User's questionnaire focusses on the importance of smartphones, the standards of applications design and the disadvantages of smartphones (see Appendix 1). The developer's questionnaire focusses on the concept of human computer interaction, the importance of human - computer interaction, HCI design principles and the challenges facing the development of mobile phone applications. The 
results which analyzed by SPSS software, descriptive and frequency test was done for both questionnaires.

\section{$4 \quad$ Results and Discussions}

\subsection{Demographic information of users}

The descriptive analysis shows that out of 150 responses, about $37 \%$ were female and $63 \%$ were male. In term of user's age, majority $54 \%$ of the respondents' age were between (25-30). In relation to qualification the majority $64 \%$ have a bachelor's degree and $16.6 \%$ have master degree. In reference to type of smartphone, $46.4 \%$ of responses use IOS phone (IPhone) while $37.1 \%$ of them use android phone, about $13.2 \%$ of users use window phone whereas $0.7 \%$ use blackberry phone and about $2 \%$ of user use Symbian phone (Nokia).

\subsection{Demographic information of developers}

The descriptive analysis shows that out of 150 responses, $38.5 \%$ were female and $57.7 \%$ were male. In term of developers' age, majority $46.2 \%$ of the respondents' age were between (31-35). In relation to experience the majority $44.2 \%$ have (3-5) years. In reference to education level, $61.5 \%$ of responses have a bachelor's degree and $28.8 \%$ have master degree.

\subsection{The importance of smart phones and their applications}

This section focusses on understanding of users about the importance of their phones (Table 2).

Table 2. The importance of smart phones and their applications

\begin{tabular}{|l|c|c|c|c|c|c|c|c|}
\hline & $\begin{array}{c}\text { Smartpho } \\
\text { nes allow } \\
\text { users to } \\
\text { secure } \\
\text { and store } \\
\text { private } \\
\text { infor- } \\
\text { mation }\end{array}$ & $\begin{array}{c}\text { Smartphone } \\
\text { to communi- } \\
\text { cate with } \\
\text { friends and } \\
\text { family from } \\
\text { anywhere }\end{array}$ & $\begin{array}{c}\text { Smart } \\
\text { devices } \\
\text { are } \\
\text { multi- } \\
\text { purpose } \\
\text { devices }\end{array}$ & $\begin{array}{c}\text { Smartphone } \\
\text { s allow us- } \\
\text { ers to down- } \\
\text { load many } \\
\text { applications }\end{array}$ & $\begin{array}{c}\text { Allows us- } \\
\text { ers to pin- } \\
\text { point geo- } \\
\text { graphic lo- } \\
\text { cations ac- } \\
\text { curately } \\
\text { sartphone } \\
\text { ers to watch } \\
\text { videos and } \\
\text { movies }\end{array}$ & $\begin{array}{c}\text { Smartphone } \\
\text { s include } \\
\text { advanced } \\
\text { systems }\end{array}$ & $\begin{array}{c}\text { There are a } \\
\text { lot of com- } \\
\text { panies that } \\
\text { have pro- } \\
\text { duced } \\
\text { many smart } \\
\text { phones }\end{array}$ \\
\hline SA & $29.8 \%$ & $32 \%$ & $55 \%$ & $64 \%$ & 44.4 & $52.3 \%$ & $20.5 \%$ & $13.2 \%$ \\
\hline A & $49.0 \%$ & $53.3 \%$ & $37.7 \%$ & $35.7 \%$ & 42.4 & $40.4 \%$ & $65.6 \%$ & $81.5 \%$ \\
\hline $\mathrm{N}$ & $11.9 \%$ & $3.6 \%$ & $8 \%$ & 0 & 8.6 & $5.3 \%$ & $8.6 \%$ & $4.6 \%$ \\
\hline $\mathrm{D}$ & $8.6 \%$ & $10.6 \%$ & $7 \%$ & 0 & 4.0 & $1.3 \%$ & $2.0 \%$ & 0 \\
\hline $\mathrm{SD}$ & 0 & 0 & 0 & 0 & 0 & 0 & 0 & 0 \\
\hline
\end{tabular}

Key: SA - strongly agree, A - agree, N - neutral, D - disagree, SD - strongly disagree

From the findings in Table 2, $49 \%$ of the users emphasized that smartphones allow users to secure and store private information because they have a phone lock system. 
Besides, $53.3 \%$ of the users noted that the smartphones allow users to communicate with friends and family from anywhere in the world easily by simply connecting to the Internet. Even so $55 \%$ of users affirmed that smart devices are multi-purpose devices, in addition to being used as a means of communication used as a means of organization; it contains an address book, a calculator, a calendar, a voice recorder, a calendar of notes, and many other features that govern personal and professional life. About $64 \%$ of the respondents agreed that smartphones allow users to download many applications, such as games, health, fitness, image editing, music creation, and many other applications. Besides, $44.4 \%$ of the users believe that smartphone allows users to pinpoint geographic locations accurately by locating where they are and learning about routes. However, $53.3 \%$ of the users strongly agreed that smartphones allow users to watch videos and movies, listen to music, and let them download games that provide them with entertainment. Likewise, $2 \%$ of the respondents disagreed that the smartphones include advanced systems such as Android, ISO and other systems. Similarly, $81.5 \%$ of the users affirmed that there are a lot of companies that have produced many smartphones has Samsung, Apple, Huawei and other companies.

\subsection{Standards to be considered in the design of smartphone applications}

This section discusses the standards of smartphones applications design which users expected (Table 3).

Table 3. Standards to be considered in the design of smartphone applications

\begin{tabular}{|l|c|c|c|c|c|c|c|}
\hline & Efficiency & Innovation & Speed & $\begin{array}{c}\text { The availabil- } \\
\text { ity of the } \\
\text { standard of } \\
\text { excellence and } \\
\text { innovation } \\
\text { one of the } \\
\text { negative } \\
\text { factors }\end{array}$ & $\begin{array}{c}\text { Smartphone } \\
\text { applications } \\
\text { should be easy } \\
\text { to use }\end{array}$ & $\begin{array}{c}\text { Smartphone } \\
\text { application de- } \\
\text { sign companies } \\
\text { test the appli- } \\
\text { cation initially } \\
\text { on a select } \\
\text { group of users } \\
\text { before launch- } \\
\text { ing it on the } \\
\text { market }\end{array}$ \\
\hline SA & $22.5 \%$ & $24.5 \%$ & $35.1 \%$ & $37.7 \%$ & $17.9 \%$ & $25.2 \%$ & $29.8 \%$ \\
\hline $\mathrm{A}$ & $49.0 \%$ & $47.7 \%$ & $45.0 \%$ & $48.3 \%$ & $58.9 \%$ & $53.0 \%$ & $46.4 \%$ \\
\hline $\mathrm{N}$ & $17.9 \%$ & $17.2 \%$ & $5.3 \%$ & $6.0 \%$ & $12.6 \%$ & $7.9 \%$ & $11.3 \%$ \\
\hline $\mathrm{D}$ & $9.9 \%$ & $9.9 \%$ & $10.6 \%$ & $4.6 \%$ & $9.9 \%$ & $10.6 \%$ & $8.6 \%$ \\
\hline $\mathrm{SD}$ & 0 & 0 & & $2.6 \%$ & 0 & $2.6 \%$ & $3.3 \%$ \\
\hline
\end{tabular}

Key: SA - strongly agree, A - agree, $\mathrm{N}$ - neutral, D - disagree, SD - strongly disagree

From the findings in Table 3, it is evident that $49 \%$ of the users believe that the efficiency is very important because the user is looking for a systematic and accurate application in the data display in line with the development of the fourth generation of smart phones. Even so, $24.5 \%$ of the users strongly agreed that the smartphones should have innovation in its design because the user is always looking for everything that is new to escape the boredom of repetition and similarity that prevails in most smart phone applications. In addition, $45 \%$ of the response affirmed that speed is one of standard of 
smartphones design due to speed is a positive factor that encourages users to interact with the application over and over without boredom. While 58.9\%) of the users noted waiting is one of the negative factors that always distracts users from using some smart phone applications. About $25.2 \%$ of the users strongly agreed that smartphone applications should be easy to use and uncomplicated to fit the largest number of users of all ages and interests without exception. Nonetheless, $46.4 \%$ of the users confirmed that smartphone application design companies test the application initially on a select group of users before launching it on the market officially as an experience through which to identify the advantages, possibilities and disadvantages of the application.

\subsection{The disadvantages of the smart phone's applications on the use}

This part focus on the users' perspective about the disadvantage of the smartphone, Table 4 shows the user response.

Table 4. The disadvantages of the smart phones applications on the user.

\begin{tabular}{|c|c|c|c|c|c|c|c|c|}
\hline & $\begin{array}{c}\text { Smartpho } \\
\text { nes cause } \\
\text { sleep } \\
\text { problems } \\
\text { and wake } \\
\text { up }\end{array}$ & \begin{tabular}{|} 
Radiation \\
from \\
Smartphone \\
s causes a \\
high risk of \\
certain dis- \\
eases
\end{tabular} & $\begin{array}{c}\text { Smart } \\
\text { phones } \\
\text { can } \\
\text { cause } \\
\text { damage, } \\
\text { fatigue } \\
\text { and re- } \\
\text { peated } \\
\text { pain }\end{array}$ & \begin{tabular}{|} 
Addiction \\
caused \\
the surf- \\
ing of so- \\
cial web- \\
sites and \\
electronic \\
games
\end{tabular} & $\begin{array}{c}\text { Smartphone } \\
\text { s may affect } \\
\text { the user's } \\
\text { culture and } \\
\text { behavior }\end{array}$ & \begin{tabular}{|c} 
Users Faces \\
Very slow \\
perfor- \\
mance
\end{tabular} & $\begin{array}{l}\text { There is } \\
\text { shortcom- } \\
\text { ing in some } \\
\text { companies } \\
\text { in the test- } \\
\text { ing of usa- } \\
\text { bility in } \\
\text { smart } \\
\text { phones and } \\
\text { their appli- } \\
\text { cations }\end{array}$ & $\begin{array}{c}\text { The inabil- } \\
\text { ity to cope } \\
\text { with } \\
\text { changes }\end{array}$ \\
\hline SA & $20.5 \%$ & $18.5 \%$ & $3.3 \%$ & $5.3 \%$ & 24.5 & $27.2 \%$ & $18.5 \%$ & 0 \\
\hline A & $49.7 \%$ & $58.9 \%$ & $55.0 \%$ & $42.4 \%$ & 52.3 & $36.4 \%$ & $43.0 \%$ & $45.7 \%$ \\
\hline $\mathrm{N}$ & $5.3 \%$ & $5.3 \%$ & $5.3 \%$ & $18.5 \%$ & 11.3 & $17.2 \%$ & $27.2 \%$ & $15.9 \%$ \\
\hline D & $15.9 \%$ & $13.2 \%$ & $24.5 \%$ & $27.2 \%$ & 7.9 & $15.2 \%$ & $10.6 \%$ & $27.2 \%$ \\
\hline SD & $7.9 \%$ & $3.3 \%$ & 0 & $6.0 \%$ & 3.3 & $3.3 \%$ & 0 & $10.6 \%$ \\
\hline
\end{tabular}

Key: SA - strongly agree, A - agree, $\mathrm{N}$ - neutral, D - disagree, SD - strongly disagree

From the findings in Table 4 , it is evident that $49.7 \%$ of the users believe that smartphones cause sleep problems and wake up when left beside the user asleep because the radiation from them leads to a defect in the secretion of melatonin, which is found in the brain and associated with the regulation of sleep. Even so, $18.5 \%$ of the users strongly agreed that the radiation from smartphones causes a high risk of certain diseases, the most common being cancer because they contain carcinogens that affect users. In addition, 55\% of the response affirmed smart phones can cause damage, fatigue and repeated pain in the wrist, neck and hand, if the muscle pressure is caused by rapid movement when writing on smart phones. While $42.4 \%$ of the users noted smartphone, addiction caused the surfing of social websites and electronic games. About $24.5 \%$ of the users strongly agreed that smartphones may affect the user's culture and behavior as a result of incorrect information that a user may experience when using the Internet. Nonetheless, $36.4 \%$ of the users confirmed that users face very slow performance through using some types of smart phones. About $10.6 \%$ of users disagree 
that there are shortcomings in some companies in the testing of usability in smart phones and their applications. Beside $45.7 \%$ of users affirmed that the inability to cope with changes and developments in smart phones and their applications.

\subsection{The concept of human - computer interaction}

This section discusses the concept of human-computer interaction (developers' perspective) (Table 5).

Table 5. The concept of human - computer interaction.

\begin{tabular}{|l|c|c|c|c|c|c|}
\hline \multicolumn{1}{|c|}{ Approach } & \multicolumn{2}{c|}{ SA } & A & N & D & SD \\
\hline $\begin{array}{l}\text { HCI are human-powered tools to achieve limited } \\
\text { goals by performing specific steps to perform com- } \\
\text { puter functions }\end{array}$ & $\%$ & 21.2 & 53.8 & 13.5 & 7.7 & 0 \\
\hline $\begin{array}{l}\text { HCI mention to scientific study of interaction be- } \\
\text { tween humans and computer }\end{array}$ & $\%$ & 21 & 25 & 4 & 0 & 0 \\
\hline HCI occurs only in the user interface & $\%$ & 11.5 & 46.2 & 5.8 & 23.1 & 9.6 \\
\hline HCI is a wide area of research and practice & $\%$ & 15.4 & 57.2 & 11.5 & 13.5 & 0 \\
\hline $\begin{array}{l}\text { HCI is interested in designing inspection, inspec- } \\
\text { tion, editing and manufacturing systems for user use }\end{array}$ & $\%$ & 15.4 & 46.2 & 17.3 & 17.3 & \\
\hline $\begin{array}{l}\text { HCI developers are monitoring ways humans inter- } \\
\text { act with computers }\end{array}$ & $\%$ & 17.3 & 61.5 & 11.5 & 5.8 & 0 \\
\hline $\begin{array}{l}\text { HCI developers monitor design techniques that al- } \\
\text { low them to interact with computers in new ways }\end{array}$ & $\%$ & 42.3 & 44.2 & 7.7 & 1.9 & 0 \\
\hline The primary focus of the HCI systems on Usability & $\%$ & 19.2 & 48.1 & 15.4 & 11.5 & 1.9 \\
\hline $\begin{array}{l}\text { The designers of the HCI public were welcomed to } \\
\text { support redesign it as a design system }\end{array}$ & $\%$ & 26.9 & 40.4 & 9.6 & 15.4 & 3.8 \\
\hline HCI refers to both interaction and interface & & 21.2 & 21.9 & 15.4 & 7.7 & 0 \\
\hline
\end{tabular}

Key: SA - strongly agree, A - agree, $\mathrm{N}$ - neutral, D - disagree, SD - strongly disagree

From the results in Table 5, about $75 \%$ of the developers define the HCI as humanpowered tools to achieve limited goals by performing specific steps to perform computer functions. Beside $46 \%$ of responses mention that the HCI is scientific study of interaction between humans and computer.in addition to, $46.2 \%$ of the developer agree that the HCI occurs only in the user interface. While $73.6 \%$ of the developers see that the HCI is a wide area of research and practice to develop and improve the smartphones and their applications. Nonetheless, $15.4 \%$ of developers strongly agree that HCI is interested in designing inspection, inspection, editing and manufacturing systems for user use. Whereas $5.8 \%$ of developers disagree that HCI developers are monitoring ways humans interact with computers. About $42.3 \%$ of developer believe that HCI developers monitor design techniques that allow them to interact with computers in new ways. The primary focus of the HCI systems on usability according to $48.1 \%$ of developers. About $21.9 \%$ of developers see that HCI refers to both interaction and interface and about $40.4 \%$ of developers affirm that the designers of the HCI public were welcomed to support redesign it as a design system. 


\subsection{The importance of human - computer interaction}

This part focus on the importance of HCI the results sort in descending based on its importance to developers (Table 6).

Table 6. The importance of human - computer interaction

\begin{tabular}{|l|c|}
\hline \multicolumn{1}{|c|}{ The importance of human - computer interaction } & $\begin{array}{c}\text { Percent of } \\
\text { response }\end{array}$ \\
\hline $\begin{array}{l}\text { A basic aim of HCI is to improve the interactions between users and computers by making } \\
\text { computers more usable and receptive to the user's needs. }\end{array}$ & $52.9 \%$ \\
\hline $\begin{array}{l}\text { Develop and improve the safety, utilization, efficiency and use of the system that includes } \\
\text { computers. }\end{array}$ & $52.9 \%$ \\
\hline Produce safe and usable systems and functional systems as well. & $49.0 \%$ \\
\hline $\begin{array}{l}\text { Identify problems and tasks (such as in the workplace) that can be addressed with software } \\
\text { products. }\end{array}$ & $49.0 \%$ \\
\hline $\begin{array}{l}\text { Design systems that minimize the barrier between the human's cognitive model of what they } \\
\text { want to accomplish and the computer's understanding of the user's task. }\end{array}$ & $43.1 \%$ \\
\hline $\begin{array}{l}\text { Involve users in the design and evaluation process. } \\
\text { HCI give the idea of user experience UX in which we can improve the computing devices and } \\
\text { application for the user. }\end{array}$ & $52.9 \%$ \\
\hline The goal of HCI is to creating highly efficient user interfaces. & $47.1 \%$ \\
\hline $\begin{array}{l}\text { The goal of HCI is to comparing user interfaces, taking into consideration the characteristics } \\
\text { of each. }\end{array}$ & $52.9 \%$ \\
\hline $\begin{array}{l}\text { The goal of HCI is to studying the human uses of computers and their integration with societal } \\
\text { cultures. }\end{array}$ & $58.8 \%$ \\
\hline
\end{tabular}

From Table 6, the descending order of importance of $\mathrm{HCI}$ as s following:

- The goal of HCI is to studying the human uses of computers and their integration with societal cultures.

- A basic aim of $\mathrm{HCI}$ is to improve the interactions between users and computers by making computers more usable and receptive to the user's needs.

- Develop and improve the safety, utilization, efficiency and use of the system that includes computers.

- HCI give the idea of user experience UX in which we can improve the computing devices and application for the user

- The goal of HCI is to comparing user interfaces, taking into consideration the characteristics of each.

- Produce safe and usable systems and functional systems as well.

- Identify problems and tasks (such as in the workplace) that can be addressed with software products.

- The goal of $\mathrm{HCI}$ is to creating highly efficient user interfaces.

- Design systems that minimize the barrier between the human's cognitive model of what they want to accomplish and the computer's understanding of the user's task.

- Design systems that minimize the barrier between the human's cognitive model of what they want to accomplish and the computer's understanding of the user's task. 


\subsection{HCI design principles}

This part discusses the principle of HCI design according to developer's perspective (Table 7).

Table 7. HCI design principle

\begin{tabular}{|c|c|c|c|c|c|c|}
\hline Approach & \multicolumn{2}{|c|}{ SA } & $\mathbf{A}$ & $\mathbf{N}$ & D & SD \\
\hline $\begin{array}{l}\text { The user can recover from a common error. It includes two kinds of } \\
\text { mistake retrieval (forward and backward). }\end{array}$ & $\%$ & 21.2 & 46.2 & 11.5 & 15.4 & 1.9 \\
\hline $\begin{array}{l}\text { Contributes to determining the user's knowledge of the model and } \\
\text { matches the suitable or specific method to use the model }\end{array}$ & $\%$ & 19.2 & 48.1 & 10.5 & 0 & 5.8 \\
\hline $\begin{array}{l}\text { Contributes to how the user handles or how to complete tasks in } \\
\text { like states. And how the user address the input and output facilities } \\
\text { of the system }\end{array}$ & $\%$ & 19.2 & 50 & 11.5 & 23.1 & 4.8 \\
\hline $\begin{array}{l}\text { Provides the user with an option or alternative to performing a task } \\
\text { by selecting any of the available options }\end{array}$ & & 18.2 & 52.9 & 15.4 & 5.8 & 3.8 \\
\hline $\begin{array}{l}\text { Allows the system to perform the task that a user can perform. } \\
\text { Where the user transmissions several tasks to the system }\end{array}$ & $\%$ & 23.1 & 40.4 & 12.5 & 4.8 & 1.9 \\
\hline The system can identify human opinions & $\%$ & 20.2 & 41.3 & 17.3 & 10.5 & 6.8 \\
\hline
\end{tabular}

Key: SA - strongly agree, A - agree, $\mathrm{N}$ - neutral, D - disagree, SD - strongly disagree

From the findings in Table 7, it is evident that $46.2 \%$ of the developers believe that the user can recover from a common error. It includes two kinds of mistake retrieval (forward and backward). Even so, 19.2\% of the developers strongly agreed that the user's knowledge of the model and matches the suitable or specific method to use the model are very important. In addition, $50 \%$ of the response affirmed one of design principle is the way of user to handle or to complete tasks in like states and how the user addresses the input and output facilities of the system. While 50\% of the developers noted that the HCI design should provide the user with an option or alternative to performing a task by selecting any of the available options. About $23.1 \%$ of the developers strongly agreed that HCI should allow the system to perform the task that a user can perform where the user transmissions several tasks to the system. Nonetheless, $20.2 \%$ of the developers confirmed that the HCI system should identify human opinions. The interface must have a control feature for how the user knows objects.

\subsection{The challenges facing the development of mobile phone applications}

This section focusses on the challenges facing the development of mobile phone applications, the result sort descending according to its importance (Table 8). 
Table 8. The challenges facing the development of mobile phone applications.

\begin{tabular}{|l|c|}
\hline \multicolumn{1}{|c|}{ The challenges facing the development of mobile phone applications } & Percent of response \\
\hline $\begin{array}{l}\text { The main challenges facing HCI are concentrated in three key components: } \\
\text { user, equipment, and software }\end{array}$ & $50.0 \%$ \\
\hline $\begin{array}{l}\text { One of the key challenges in mobile application development is that there are } \\
\text { many standards for portable device platform }\end{array}$ & $46.0 \%$ \\
\hline $\begin{array}{l}\text { Limits the development of mobile phone applications Incompatibility of plat- } \\
\text { forms, because of different programming languages }\end{array}$ & $46.0 \%$ \\
\hline $\begin{array}{l}\text { Limits the development of mobile phone applications the Recurrent Version Re- } \\
\text { leases }\end{array}$ & $50.0 \%$ \\
\hline $\begin{array}{l}\text { HCI designers face important challenges in how to keep abreast of changes in } \\
\text { technology }\end{array}$ & $50.0 \%$ \\
\hline $\begin{array}{l}\text { HCI designers face important challenges in how to ensure their design provides } \\
\text { good HCI }\end{array}$ & $52.0 \%$ \\
\hline $\begin{array}{l}\text { The challenge of designing HCI is not just about how to design effective ac- } \\
\text { count-based representations in complex web environments }\end{array}$ & $42.0 \%$ \\
\hline $\begin{array}{l}\text { The challenge of designing HCI confront complex social, culture, and political } \\
\text { issues like control of attention }\end{array}$ & $52.0 \%$ \\
\hline $\begin{array}{l}\text { The rapid development of mobile devices is a challenge for HCI, which chal- } \\
\text { lenges the continued development of applications and software }\end{array}$ & $38.0 \%$ \\
\hline
\end{tabular}

From Table 8 , the descending order of the challenges facing the development of mobile phone applications as following:

- The challenge of designing HCI confront complex social, culture, and political issues like control of attention.

- HCI designers face important challenges in how to ensure their design provides good HCI.

- The main challenges facing HCI are concentrated in three key components: user, equipment, and software.

- Limits the development of mobile phone applications the Recurrent Version Releases.

- HCI designers face important challenges in how to keep abreast of changes in technology

- One of the key challenges in mobile application development is that there are many standards for portable device platform.

- Limits the development of mobile phone applications Incompatibility of platforms, because of different programming languages.

- The challenge of designing HCI is not just about how to design effective accountbased representations in complex web environments

- The rapid development of mobile devices is a challenge for HCI, which challenges the continued development of applications and software.

The study showed that developing the mobile phone in smart ways and designing unique and distinctive applications contribute to finding a positive. 


\section{Conclusion}

The idea of designing interaction between humans and computers is very rich, both in terms of the disciplines they derive from and the opportunities for research. This research was just discussing a small subset of subjects contained in the HCI. A study on the design of interaction between human and computer, especially in the field of mobile devices and applications. And some operating systems related to smart phone applications.

This area has just begun (in fact, the number of papers written on this subject has increased in the last few years), and there is much that we do not yet know about how the human mind works, allowing more user interfaces.

The results of the statistical analysis showed the importance of smart phones for users such as communication with people from anywhere, the possibility of downloading many applications, watching videos and geolocation. In addition to, the results identified the criteria that should be taken into account in the design of smart phone applications such as efficiency, innovation, responsiveness, reduce the waiting time for applications and affirmed that the importance of the application experience by some users before launching in the market. The study pointed out the main disadvantages of using smart phones such as: causing problems of insomnia, fatigue, pain, addiction to electronic games and their impact on the culture and behavior of users thus to the decline in performance.

Based on the views of the developers, the study defined HCI as science examines the design and use of computer technology, focusing on interfaces between people (users) and computers, in addition, HCI is a broad field of research, practice and development, with an interest in designing inspection, editing and manufacturing systems. Developers monitor human interaction with computers and the main focus of $\mathrm{HCI}$ is on usability which is mean the ease of learning. The importance of HCI focus on making computers more uses and met users' needs, as well as to improve and develop the effectiveness of computer systems and identifying tasks and problems that may face software. When designing HCI systems, developers take into account the ability of the user to recover from common errors, the system should contribute to determining the user's knowledge of the model and contribute to the user's handling of similar situations. The main challenges facing HCI are concentrated in three main elements: user, hardware, and software. In addition to, some users with cognitive deficits are therefore they the most problematic individuals when dealing with technological applications, mobile devices are evolving rapidly so there is challenge of continuous development of applications and software and data processing in different applications is also one of the most important challenges facing the use of different applications.

\subsection{Recommendations and future studies}

After studying the results of the study, the researcher concluded that designing the interaction between human and computer in the development of mobile phone has many benefits. The researcher recommends the following: 
- The researcher interested in the design of smart phone applications recommends a more in-depth study in terms of design in order to reach a good quality of applications.

- The researcher is recommended to undertake a study to discover the priorities of HCI rules as perform through mobile developers.

- A similar study is to evaluate websites and scholar projects and come up with a group of measures to confirm that the design is appropriate.

- Making usability tests for programs, applications and websites.

- Qualify and train users with cognitive deficits in an appropriate manner to enable them to make better use of programs and applications.

\section{References}

[1] Norman, K.L. (2017). Cyberpsychology: An introduction to human-computer interaction. Cambridge university press, UK.

[2] bin Abdul Rashid, N., bin Othman, M. Z., bin Johan, R., \& Sidek, S. F. B. H. (2019). Cisco Packet Tracer Simulation as Effective Pedagogy in Computer Networking Course. International Journal of Interactive Mobile Technologies (iJIM), 13(10): 4-18. https://doi.org/10. $\underline{\text { 3991/ijim.v13i10.11283 }}$

[3] Vainio, T., Oksman, V., Wigelius, H., Markova, M., \& Kulju, M. (2008). Exploring the Transformations of Interaction in Mobile Work Contexts. International Journal of Interactive Mobile Technologies, 2(2): 24-31.

[4] Wich, M., Kramer, T. (2015). Enhanced human-computer interaction for business applications on mobile devices: a design-oriented development of a usability evaluation questionnaire. In 2015 48th Hawaii International Conference on System Sciences, IEEE, pp. 472-481. https://doi.org/10.1109/hicss.2015.63

[5] Carroll, J.M. (1997). Human-computer interaction: psychology as a science of design. Annual review of psychology, 48(1): 61-83.

[6] Clemmensen, T. (2006). Whatever happened to the psychology of human-computer interaction? A biography of the life of a psychological framework within a HCI journal. Information Technology \& People, 19(2): 121-151. https://doi.org/10.1108/0959384061 $\underline{0673793}$

[7] Bailey, S., Vidyarthi, J. (2010). Human-computer interaction: The missing piece of the records management puzzle? Records Management Journal, 20(3): 279-290. https://doi. org/10.1108/09565691011095300

[8] Pearson, J., Buchanan, G., Thimbleby, H. (2010). HCI design principles for ereaders. In Proceedings of the third workshop on Research advances in large digital book repositories and complementary media, ACM, pp. 15-24. https://doi.org/10.1145/1871854.1871860

[9] Carroll, J.M. (2014). The neighborhood in the Internet: Design research projects in community informatics. Routledge.

[10] Wright, P., McCarthy, J. (2010). Experience-centered design: designers, users, and communities in dialogue. Synthesis Lectures on Human-Centered Informatics, 3(1): 1-123. https://doi.org/10.2200/s00229ed1v01y201003hci009

[11] Banga, C., Weinhold, J. (2014). Essential mobile interaction design: Perfecting interface design in mobile apps. Pearson Education.

[12] Taba, S. (2014). Empirical Studies on the Relation between User Interface Design and Perceived Quality of Android Applications. Master thesis, Queen's University, Canada. 
[13] Al-Aydani, M. (2010). The impact of some smart device applications on development English Speaking Skills for Third Year Secondary Students. Master thesis, Umm AL-Qura University, Saudi Arabia. https://doi.org/10.21474/ijar01/2872

[14] Annapurna, K.V.S., Murty, Y.S. (2016). A Comparative Study on Mobile Platforms (Android vs. IOS). International Journal of Advanced Research in Computer Engineering \& Technology, 5(3): 547-553.

[15] Ribeiro, A., da Silva, A.R. (2014). Development of mobile applications using a modeldriven software development approach. Instituto Superior Técnico Lisbon, Portugal.

[16] Ozturk, Y. (2017). Development of a Model for Simple Educational Mobile Applications: A Case Study of Evaluation Matrix. Master thesis, Seoul National University.

[17] Karlson, A.K., Iqbal, S.T., Meyers, B., Ramos, G., Lee, K., Tang, J.C. (2010). Mobile taskflow in context: a screenshot study of smartphone usage. In Proceedings of the SIGCHI Conference on Human Factors in Computing Systems, ACM, pp. 2009-2018. https://doi.org/10.1145/1753326.1753631

\section{Authors}

Nidal Al Said is from Ajman University, Ajman, United Arab Emirates. E mail: n.alsaid@ajman.ac.ae

Khaleel M. Al-Said is from Middle East University, Amman, Jordan. E mail: kalsaid@meu.edu.jo

Article submitted 2020-02-26. Resubmitted 2020-04-20. Final acceptance 2020-04-22. Final version published as submitted by the authors. 


\section{Appendix}

\section{Questionnaire on human computer interaction}

With the scientific revolution of technology and its versatility in the present era, the term human computer interaction (HCI) emerged. It is a science that deals with how human interaction with computers, regardless of their different forms and functions, and then developing them to produce a successful and easy interaction environment. This research project is concerned with Identify the role of interaction between human and computer in the development of mobile devices, Categorize the kind of the connection between the user and the smartphone, and Identify the challenges facing the development of mobile phone applications. To achieve these objectives, this questionnaire tool has been prepared and will be applied to a sample of developers and interested in the field of interaction between human and computer. I therefore kindly request that you fill out the following questionnaire, so that I can gather the necessary data for this study. Please be assured that any information that you provide in this survey will be treated as confidential and the collected data will be used purely for academic research. You and your responses will not be identifiable in any published outcomes.

This questionnaire will require no more than 5-10 minutes of your time to complete. Moreover, your participation in this study is completely voluntary and you consequently have the right to withdraw for any reason and at any time. Should you choose to do so, your responses will be immediately and securely destroyed.

I wish to thank you in advance for giving your precious time to participate in this study. If you have any further inquiries and require more explanation, please feel free to contact me using the contact details provided.

With best regards,

\section{Part 1: General information}

This section is designed to gather general information about you as a user of computers or developer in the field of HCL. First, please choose the most appropriate option in each of the following questions by entering a tick $(\sqrt{ })$ in the box next to it:

\section{Gender:}

$\square$ Male $\quad \square$ Female

\section{Age:}

$$
\square \text { 25-30 years } \square 31-35 \text { years } \square 36-40 \text { years } \square 40+\text { years }
$$

\section{Number of years of experience:}

$\square$ less than 3 years $\square$ 3-5 years $\square 5-10$ years $\square 10$ to 20 years $\square$ More than 20 years

\section{Qualifications:}

$$
\text { Degree }
$$

$\square$ High School Certificate $\square$ Bachelor's Degree $\square$ Master's Degree $\square$ Doctoral 
Part 2

\begin{tabular}{|c|c|c|c|c|c|c|}
\hline \multicolumn{7}{|c|}{ The concept of human - computer interaction. } \\
\hline No & Question & $S A$ & $\boldsymbol{A}$ & $N$ & $D$ & $S D$ \\
\hline 1. & $\begin{array}{l}\text { HCI are human-powered tools to achieve limited goals by } \\
\text { performing specific steps to perform computer functions. }\end{array}$ & & & & & \\
\hline 2. & $\begin{array}{l}\text { HCI mention to scientific study of interaction between hu- } \\
\text { mans and computer. }\end{array}$ & & & & & \\
\hline 3. & HCI occurs only in the user interface. & & & & & \\
\hline 4. & HCI is a wide area of research and practice. & & & & & \\
\hline 5. & $\begin{array}{l}\mathrm{HCI} \text { is interested in designing inspection, inspection, editing } \\
\text { and manufacturing systems for user use. }\end{array}$ & & & & & \\
\hline 6. & $\begin{array}{l}\text { HCI developers are monitoring ways humans interact with } \\
\text { computers. }\end{array}$ & & & & & \\
\hline 7. & $\begin{array}{l}\text { HCI developers monitor design techniques that allow them } \\
\text { to interact with computers in new ways. }\end{array}$ & & & & & \\
\hline 8. & The primary focus of the HCI systems on Usability. & & & & & \\
\hline 9. & $\begin{array}{l}\text { The designers of the HCI public were welcomed to support } \\
\text { redesign it as a design system. }\end{array}$ & & & & & \\
\hline & HCI refers to both interaction and interface. & & & & & \\
\hline \multicolumn{7}{|c|}{ The importance of human - computer interaction } \\
\hline No & Question & $S A$ & $\boldsymbol{A}$ & $N$ & $D$ & $S D$ \\
\hline 1. & $\begin{array}{l}\text { A basic aim of HCI is to improve the interactions between } \\
\text { users and computers by making computers more usable and } \\
\text { receptive to the user's needs. }\end{array}$ & & & & & \\
\hline 2. & $\begin{array}{l}\text { Develop and improve the safety, utilization, efficiency and } \\
\text { use of the system that includes computers. }\end{array}$ & & & & & \\
\hline 3. & $\begin{array}{l}\text { Produce safe and usable systems and functional systems as } \\
\text { well. }\end{array}$ & & & & & \\
\hline 4. & $\begin{array}{l}\text { Identify problems and tasks (such as in the workplace) that } \\
\text { can be addressed with software products. }\end{array}$ & & & & & \\
\hline 5. & $\begin{array}{l}\text { Design systems that minimize the barrier between the hu- } \\
\text { man's cognitive model of what they want to accomplish and } \\
\text { the computer's understanding of the user's task. }\end{array}$ & & & & & \\
\hline 6. & Involve users in the design and evaluation process. & & & & & \\
\hline 7. & $\begin{array}{l}\text { HCI give the idea of user experience UX in which we can } \\
\text { improve the computing devices and application for the user. }\end{array}$ & & & & & \\
\hline 8. & $\begin{array}{l}\text { The goal of HCI is to creating highly efficient user inter- } \\
\text { faces. }\end{array}$ & & & & & \\
\hline 9. & $\begin{array}{l}\text { The goal of HCI is to comparing user interfaces, taking into } \\
\text { consideration the characteristics of each. }\end{array}$ & & & & & \\
\hline 10. & $\begin{array}{l}\text { The goal of HCI is to studying the human uses of computers } \\
\text { and their integration with societal cultures. }\end{array}$ & & & & & \\
\hline \multicolumn{7}{|c|}{ The principles in the design of the phones and their applications. } \\
\hline No & Question & $S A$ & $\boldsymbol{A}$ & $N$ & $\boldsymbol{D}$ & $S D$ \\
\hline 1. & HCI does not care about exterior appearance. & & & & & \\
\hline 2. & $\begin{array}{l}\text { Knowing how to use a UI development tool, doesn't mean } \\
\text { you can make a usable inter face. }\end{array}$ & & & & & \\
\hline 3. & $\begin{array}{l}\text { The most relevant principles appear to be consistency, inter- } \\
\text { connection and replacement. }\end{array}$ & & & & & \\
\hline 4. & $\begin{array}{l}\text { The design of the phone requires a slightly different princi- } \\
\text { ples from the design of the computer. }\end{array}$ & & & & & \\
\hline
\end{tabular}


5. Good design of $\mathrm{HCI}$ is essential to the success of computer and information systems.

6. Perception is one of the most fundamental principles that must be observed in HCI.

$7 . \quad$ Focusing on the user and determining the number of users desired and targeted are the basic principles of HCI.

8. The need to test HCI on a sample of users is one of the basic principles in the design of smart phones and their applications.

The challenges facing the development of mobile phone applications.

\begin{tabular}{|c|c|c|c|c|c|c|}
\hline No & Question & $S A$ & $A$ & $N$ & $D$ & $S D$ \\
\hline 1. & $\begin{array}{l}\text { The main challenges facing HCI are concentrated in three } \\
\text { key components: user, equipment, and software. }\end{array}$ & & & & & \\
\hline 2. & $\begin{array}{l}\text { One of the key challenges in mobile application develop- } \\
\text { ment is that there are many standards for portable device } \\
\text { platform. }\end{array}$ & & & & & \\
\hline 3. & $\begin{array}{l}\text { Limits the development of mobile phone applications In- } \\
\text { compatibility of platforms, because of different program- } \\
\text { ming languages. }\end{array}$ & & & & & \\
\hline 4. & $\begin{array}{l}\text { Limits the development of mobile phone applications the } \\
\text { Recurrent Version Releases. }\end{array}$ & & & & & \\
\hline 5. & $\begin{array}{l}\text { HCI designers face important challenges in how to keep } \\
\text { abreast of changes in technology }\end{array}$ & & & & & \\
\hline 6. & $\begin{array}{l}\text { HCI designers face important challenges in how to ensure } \\
\text { their design provides good HCI. }\end{array}$ & & & & & \\
\hline 7. & $\begin{array}{l}\text { The challenge of designing HCI is not just about how to de- } \\
\text { sign effective account-based representations in complex web } \\
\text { environments }\end{array}$ & & & & & \\
\hline 8. & $\begin{array}{l}\text { The challenge of designing HCI confront complex social, } \\
\text { culture, and political issues like control of attention. }\end{array}$ & & & & & \\
\hline 9. & $\begin{array}{l}\text { The rapid development of mobile devices is a challenge for } \\
\text { HCI, which challenges the continued development of appli- } \\
\text { cations and software. }\end{array}$ & & & & & \\
\hline
\end{tabular}

Key: SA - strongly agree, A - agree, $\mathrm{N}$ - neutral, D - disagree, SD - strongly disagree 